\section{JURNAL ABDIMAS

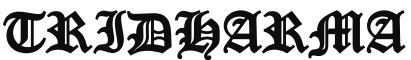

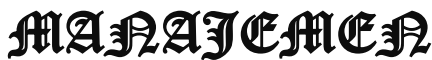

P-ISSN 2615-6849, E-ISSN 2622-3686

Jurnal ABDIMASVol.1,No.3,September 2020,Hal(121-128)

@Prodi Manajemen Fakultas Ekonomi Universitas Pamulang

Email: abdimasjurnal.unpam@gmail.com Telp: (021) 741-2566

\title{
OPTIMALISASI PERAN MAJELIS TAKLIM \\ DALAM PENDIDIKAN DAN PEMBANGUNAN
}

\author{
Nurismalatri, Yuga Pratama, Siti Aisyah Nurrizki Rahmadania, \\ Djoko Prasetyo, Siti Aesah
}

Dosen Fakultas Ekonomi Universitas Pamulang

Email dosen00996@unpam.ac.id, dosen02112@unpam.ac.id,

dosen02183@unpam.ac.id, dosen02376@unpam.ac.id,dosen01223@unpam.ac.id

\begin{abstract}
ABSTRAK
Tujuan kegiatan Pengabdian Kepada Masyarakat yang berjudul " Optimalisasi Peran Majelis Taklim Dalam pendidikan Dan Pembangunan" merupakan bentuk pelaksanaan kewajiban Tri Dharma Perguruan Tinggi. Tempat Kegiatan dilakukan pada masyarakat yang aktif dalam Majelis Taklim Fathul Khair yang beralamat di Pamulang Lestari Residence, Pamulang Barat, Pamulang, Tangerang Selatan, Banten pada tanggal 15 hingga 17 April 2020.

Kegiatan Pengabdian kepada masyarakat ini dalam rangka memberikan informasi mengenai pendidikan yang tepat di lingkungan rumah dan lingkungan masyarakat serta bagaimana hubungan yang baik antara masyarakat dan sekolah. Hal ini guna menumbuhkan dan mengembangkan potensi anak agar tumbuh dan berkembang sesuai dengan nilai-nilai yang ada di dalam masyarakat dan kebudayaan bangsa.

Metode yang digunakan pada kegaiatan pengabdian kepada masyarakat ini adalah ceramah dan diskusi. Ceramah yaitu penyampaian materi secara lisan dengan efektif, efisien dan menyenangkan melalui bantuan media pembelajaran buku dan video. Sedangkan metode diskusi digunakan agar peserta fokus dan aktif dengan sharing pengalaman belajar di rumah masing masing dan fenomena fenomena pendidikan dunia sehingga menemukan pemecahan masalah pendidikan yang dihadapi.

Hasil Pengabdian Kepada Masyarakat yang diperoleh adalah orang tua bersedia berperan penuh dalam pendidikan baik pendidikan kepribadian, pendidikan keagamaan dan pendidikan umum dan menjalin hubungan yang baik serta berperan aktif dengan pihak sekolah dan lembaga masyarakat lainnya dalam mengembangkan pendidikan yang membangun akhlak mulia.
\end{abstract}

Kata Kunci : Pengabdian, masyarakat, pendidikan, pembangunan

\begin{abstract}
The purpose of the community service activity entitled "Optimizing the Role of the Taklim Council in education and development" is a form of implementation of the Tri Dharma of Higher Education obligations. Place of activity carried out in communities who are active in the Fathul Khair Taklim Council which is located at Pamulang Lestari Residence, Pamulang Barat, Pamulang, South Tangerang, Banten on April 15 to 17, 2020.

This community service activity is in order to provide information about proper education in the home environment and community environment as well as how
\end{abstract}




\section{JURNAL ABDIMAS

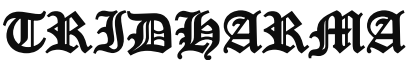

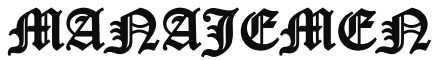

P-ISSN 2615-6849, E-ISSN 2622-3686

Jurnal ABDIMASVol.1,No.3,September 2020,Hal(121-128)

@Prodi Manajemen Fakultas Ekonomi Universitas Pamulang

Email: abdimasjurnal.unpam@gmail.com Telp: (021) 741-2566

good relations are between the community and the school. This is to foster and develop children's potential so that they grow and develop in accordance with the values that exist in society and the nation's culture.

The methods used in community service activities are lectures and discussions. Lecture is the delivery of material orally in an effective, efficient and fun way through the help of learning media books and videos. While the discussion method is used so that participants focus and be active by sharing learning experiences in their respective homes and the phenomenon of world education phenomena so as to find solutions to educational problems faced.

The results of community service obtained are that parents are willing to play a full role in education both in personality education, religious education and general education and to establish good relationships and play an active role with schools and other community institutions in developing education that builds noble morals.

\section{Keywords: Community service, education, development}

\section{PENDAHULUAN}

Pendidikan dan pembangunan tidak dapat dipisahkan karena pendidikan memiliki peran yang sangat penting dalam kehidupan berbangsa dan bernegara, yakni menciptakan sumber daya manusia yang berkualitas sebagai upaya meningkatkan kesejahteraan rakyat.

Pendidikan mempengaruhi secara penuh pertumbuhan ekonomi suatu negara. Hal ini bukan saja karena pendidikan akan berpengaruh terhadap produktivitas, tetapi juga akan berpengaruh pada kemampuan mendapatkan penghasilan.

Arah pembangunan mengacu pada Rencana Pembangunan Jangka Menengah Nasional (RPJMN) 20202024 mengutamakan peningkatan pemerataan layanan pendidikan berkualitas. Kondisi tingkat pendidikan masyarakat telah membaik, namun belum menjangkau seluruh penduduk.

Kesenjangan

pendidikan antarkelompok ekonomi masih menjadi permasalahan dan semakin lebar seiring dengan semakin tingginya jenjang pendidikan. Kesenjangan pendidikan juga masih tinggi apabila dibandingkan antarwilayah. (BPS, 2019)

Fenomena pendidikan juga dihantui dengan degradasi moral yang terjadi dan sedang melanda bangsa ini yang menurut Supardi (2012) hal ini merupakan indikasi kegagalan pembangunan bidang pendidikan. Korupsi yang merajalela, tindak kekerasan, tawuran, penyalahgunaan narkotika ada pada hampir semua lapisan masyarakat, mulai dari artis atau public figure, pejabat, hingga pelajar dan rakyat jelata, begitu juga dengan gaya hidup hedonisme, yang lebih mengutamakan dan mementingkan aspek dengan mementingkan seolah olah berlimpah materi padahal hasil pinjaman.

Gambaran tersebut merupakan sebagian dari contoh-contoh penyakit moral bangsa yang masih menjadi PR untuk dihadapi dengan kepedulian orangtua dan masyarakat dalam memberantas dan menghilangkannya.

Permasalahan lainnya yang mendasar dalam meningkatkan dan mengembangkan peran startegis keluarga untuk mendidik tumbuh kembang anak usia dini masih belum 


\section{JURNAL ABDIMAS

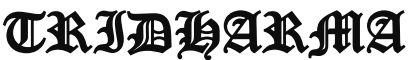

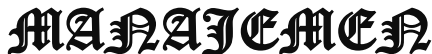

P-ISSN 2615-6849, E-ISSN 2622-3686

Jurnal ABDIMASVol.1,No.3,September 2020,Hal(121-128)

@ Prodi Manajemen Fakultas Ekonomi Universitas Pamulang

Email: abdimasjurnal.unpam@gmail.com Telp: (021) 741-2566 ditangani dengan baik. Beberapa permasalah mendasar yang membutuhkan alternatif pemecahannya adalah:

1. Kondisi-kondisi apa saja yang dapat melatar belakangi perlunya pembinaan dan pengembangan keluarga dalam pendidikan anak

2. Peran apakah yang perlu dilakukan keluarga dan masyarakat dalam pendidikan anak

3. Bagaimana bentuk-bentuk program alternatif manakah yang dapat dipilih dan disosialisaikan oleh pemerintah untuk membimbing dan membina orang tua (keluarga) dan calon orang tua dalam pendidikan anak

Masyarakat merupakan komponen utama terselenggaranya proses pendidikan. Kontribusi masyarakat di lingkungan sekolah perlu dioptimalkan sebagai upaya pemberdayaan dalam rangka mewujudkan visi dan misi sekolah dengan paradigma pendidikan yang baru. Masyarakat dapat memberikan sumbangsihnya kepada sekolah dengan memberikan masukanmasukan terutama dalam penyusunan program-program sekolah. Demikian juga dalam pelaksanaan program, dukungan masyarakat perlu dioptimalkan. Rencana Pengembangan Sekolah dibuat bersama-sama oleh sekolah dan masyarakat, disampaikan secara terbuka, diperbaharui setiap tahun, dan dilaksanakan.

Peningkatan peran serta masyarakat dapat dilakukan dalam bentuk peningkatan kondisi lingkungan sekolah yang mendukung pembelajaran anak. Untuk itu, sekolah perlu menggalang hubungan baik dengan masyarakat. Sekolah memiliki programprogram yang perlu dipahami masyarakat, dan sekolah juga perlu mendengarkan saran-saran dari masyarakat.

Dengan hubungan yang baik antara sekolah dan masyarakat, terjalin persatuan antara guru dan orang tua yang secara bersama-sama dapat memenuhi kebutuhan pendidikan peserta didik dan peningkatan mutu belajar. Selain itu masyarakat dapat memantau dan menilai programprogram sekolah agar tercipta transparasi dan akuntabilitas sekolah. Apabila jalinan antara sekolah dan masyarakat tercipta dengan baik, maka dukungan dan bantuan masyarakat terhadap pemeliharaan dan peningkatan program sekolah pun akan kian terbuka.

Masyarakat harus terlibat dalam peningkatan mutu pendidikan di sekolah, salah satu di antaranya ialah karena adanya keterbatasan pemerintah dalam pengadaan sarana dan prasarana sekolah. Pendidikan yang baik tentu memerlukan pembiayaan yang tidak sedikit. Simpati masyarakat terhadap sekolah perlu dibangun agar masyarakat juga memberikan kontribusinya secara aktif dan optimal.

Melalui keterlibatan masyarakat, maka kegiatan operasional, kinerja, dan produktivitas sekolah diharapkan dapat terbantu. Namun demikian, harus diingat bahwa peran serta, dukungan, dan simpati masyarakat terhadap peningkatan mutu pendidikan tidaklah datang dengan sendirinya. Sekolah perlu secara proaktif dan kreatif mengembangkan hubungan kerjasama yang harmonis dan sinergis dengan masyarakat.

Partisipasi masyarakat merupakan keterlibatan masyarakat secara nyata dalam suatu kegiatan. Masyarakat dapat menyumbangkan gagasan, membantu tenaga, memberikan kritik yang membangun, memberikan motivasi, 


\section{JURNAL ABDIMAS

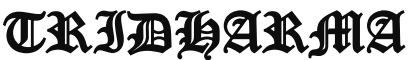

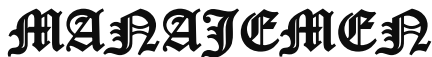

P-ISSN 2615-6849, E-ISSN 2622-3686

Jurnal ABDIMASVol.1,No.3,September 2020,Hal(121-128)

@Prodi Manajemen Fakultas Ekonomi Universitas Pamulang

Email: abdimasjurnal.unpam@gmail.com Telp: (021) 741-2566 menyumbangkan keahlian, serta memberikan dukungan terhadap pelaksanaan pendidikan.

Melihat pentingnya peran masyarakat dalam upaya peningkatan mutu pendidikan, maka pihak sekolah perlu memberdayakan mereka. Partisipasi masyarakat tidak akan muncul sendirinya. Tak sedikit di antara mereka yang masih berpandangan bahwa pendidikan sebatas urusan pemerintah, sekolah, dan para guru. Hal ini banyak terjadi di negara-negara yang sedang berkembang. Berbeda dengan masyarakat pada negara maju dan negara industri. Mereka sadar betul bahwa pendidikan merupakan tanggung jawab bersama.

Berdasarkan fenomena dan permasalahan pendidikan yang diungkapkan di atas, maka pengabdian kepada masyarakat (PKM) ini mengambil Tema " Optimalisasi Peran Majelis Taklim dalam pendidikan dan Pembangunan" kepada masyarakat di Pamulang Lestari Residence, Tangerang Selatan.

\section{RUMUSAN MASALAH}

Berdasarkan latar belakang diatas dapat dirumusan permasalahan sebagai berikut:

1. Bagaimana memberikan pemahaman mendalam mengenai peran serta orangtua dan masyarakat dalam pendidikan di lingkungan rumah ?

2. Bagaimana memberikan pemahaman mengenai hubungan antara masyarakat dengan sekolah dalam mengembangkan pendidikan?

\section{TUJUAN PELAKSANAAN}

Tujuan dari kegiatan pengabdian kepada masyarakat ini adalah:

1. Memberikan informasi terkait pendidikan yang tepat dalam lingkungan rumah dan lingkungan masyarakat.
2. Memberikan informasi tentang bagaimana hubungan yang baik antara masyarakat dan sekolah.

\section{TINJAUAN PUSTAKA}

Pengertian pendidikan dalam Undang Undang No. 20 Tahun 2003 Pasal 1 ayat 1 yakni usaha sadar dan terencana untuk mewujudkan suasana belajar dan proses pembelajaran agar peserta didik secara aktif mengembangkan potensi dirinya untuk memiliki kekuatan spiritual keagamaan, pengendalian diri, kepribadian, kecerdasan, akhlak mulia, serta keterampilan yang diperlukan dirinya, masyarakat, bangsa dan Negara.

Pendidikan dapat menjadikan sumber daya manusia lebih cepat mengerti dan siap dalam menghadapi perubahan dan pembangunan suatu negara. Peran serta masyarakat peran serta masyarakat adalah kontribusi, sumbangan, dan keikutsertaan masyarakat dalam menunjang upaya peningkatan mutu pendidikan. Pada masa sekarang, perencanaan, pelaksanaan, dan monitoring pendidikan melibatkan peran serta masyarakat.

Dalam Undang-Undang Nomor 20 Tahun 2003 tentang Sistem Pendidikan Nasional, Bab XV Pasal 54 dinyatakan bahwa:

1. Peran serta masyarakat dalam pendidikan meliputi peran serta perseorangan, kelompok, keluarga, organisasi profesi, pengusaha, dan organisasi kemasyarakatan dalam penyelenggaraan dan pengendalian mutu layanan pendidikan.

2. Masyarakat dapat berperan serta sebagai sumber pelaksana dan pengguna hasil pendidikan.

3. Ketentuan mengenai peran serta masyarakat sebagaimana dimaksud 


\section{JURNAL ABDIMAS

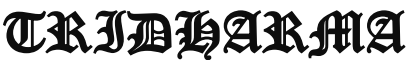

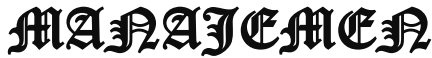

P-ISSN 2615-6849, E-ISSN 2622-3686

Jurnal ABDIMASVol.1,No.3,September 2020,Hal(121-128)

@ Prodi Manajemen Fakultas Ekonomi Universitas Pamulang

Email: abdimasjurnal.unpam@ gmail.com Telp: (021) 741-2566 pada ayat (1) dan (2) diatur lebih lanjut dengan peraturan pemerintah.

Megawanti (2012) mengemukakan bahwa pada fase input, orangtua memiliki kontribusi besar dalam memperkenalkan nilai-nilai baik kepada anak-anak mereka.

Orangtua bertanggung jawab penuh untuk mendidik anak-anak mereka dengan nilai-nilai kepemimpinan, sehingga mereka mempunyai bekal yang cukup untuk menjadi cikal bakal pemimpin ketika mereka mulai memasuki institusi formal, seperti sekolah. Pada fase proses, orangtua bekerjasama dengan para guru dan kepala sekolah untuk memberikan penguatan kepada peserta didik dalam menerapkan nilai-nilai kepempinan yang baik melalui budaya organisasi di sekolah. Sedangkan pada tahap output, peserta didik harus menghadapi begitu banyak tantangan di dunia nyata, di luar sekolah.

Peran orangtua akan berhasil menurut Aressa dkk (2016) bila terjadi komunikasi interpersonal anak dan orangtua dengan baik dengan memperhatikan faktor faktor yang dpat mempenagruhi komunikasi itu sendiri seperti citra diri, suasana psikologis, lingkungan fisik, kepemimpinan, bahasa yang digunakan dan perbedaan usia.

Dengan kualitas hubungan yang baik antara anak dan orangtua, dapat membuat anak merasa dicintai, memiliki rasa percaya diri dan menikmati kesertaan mereka dalam aktivitas bersama orangtua sehingga kondisi ini menjadi kondisi terbaik orangtua dalam mendidik anak

Menurut Sudarsana (2016), Perbaikan mutu proses dan produk pendidikan luar sekolah dan pembelajaran masyarakat serta pengembangan ilmu pengetahuan, teknologi dan kebudayaan merupakan factor penting dalam proses kemajuan umat manusia.

Dengan adanya pembangunan pendidikan maka dapat meningkatkan pembangunan ekonomi dengan kata lain terdapat hubungan yang saling terkait atau "reciprocal relationship". Makin tinggi tingkat pendidikan rata-rata penduduk, makin tinggi pula tingkat pertumbuhan ekonomi suatu negara.

Berdasarkan hal tersebut, terdapat dua hal yang menjadi fokus dalam kegiatan ini, yaitu mengenai pentingnya peran serta orangtua dan masyarakat dalam peningkatan mutu pendidikan dan menjalin hubungan yang baik dengan sekolah.

\section{METODE PELAKSANAAN}

Metode kegiatan ini berupa Ceramah dan diskusi, berikut ini adalah tahapan pelatihan yang dilakukan:

1. Tahap Persiapan

Tahap persiapan yang dilakukan meliputi:

a) Survey awal, pada tahap ini dilakukan survei ke lokasi Mushola Fathul Khair, Pamulang Lestari Residence, Pamulang Barat, Pamulang, Tangerang Selatan

b) Penyusunan bahan/materi optimalisasi peran orantua dalam pendidikan

2. Tahap Pelaksanaan

Metode penyampaian materi dilaksanakan dengan metode ceramah dan diskusi.

\section{a. Metode Ceramah}

Metode ceramah digunakan untuk menyampaikan materi secara lisan untuk menjelaskan bahan materi secara gamblang dan menyeluruh

b. Metode Diskusi

Metode Diskusi digunakan untuk mengetahui permasalahan pendidikan di rumah yang dihadapi secara mendalam dan mencari solusi bersama yang terbaik.

\section{HASIL DAN PEMBAHASAN}

Kegiatan Pengabdian Masyarakat diselenggarakan pada tanggal 15 April 


\section{JURNAL ABDIMAS

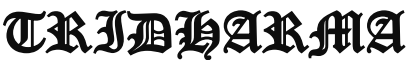

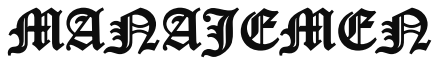

P-ISSN 2615-6849, E-ISSN 2622-3686

Jurnal ABDIMASVol.1,No.3,September 2020,Hal(121-128)

@ Prodi Manajemen Fakultas Ekonomi Universitas Pamulang

Email: abdimasjurnal.unpam@ gmail.com Telp: (021) 741-2566
2020 sampai dengan 17 April 2020 oleh dosen Universitas Pamulang diantaranya yaitu Nurismalatri, SEI, MM., Yuga Pratama, S.Kom, MM., Siti Aisyah Nurrizki Rahmadani, S.Ip., MM, Djoko Prasetyo, SE, MM., dan Siti Aesah SHI, MM.

Berdasarkan angket yang disebarkan kepada warga Pamulang Lestari Residence sebanyak 115 Kepala Keluarga, dimana 91,3 \% merupakan lulusan Sarjana S1. Alasan pemilihan sekolah yang menjadi pilihan responden sebanyak 78,3\% adalah kualitas sekolah yang baik baru kemudian $13 \%$ nya memilih sekolah karena tempatnya yang dekat dengan rumah.

Meskipun rata rata responden adalah karyawan swasta namun tetap mendukung anak sekolah dengan mengantar anak ke sekolah pada pagi hari sebanyak $69,6 \%$. $100 \%$ responden bertanya perihal pelajaran dan tugas sekolah, namun waktu dalam mendampingi anak belajar kebanyakan hanya dilakukan dalam waktu 1 jam dengan jumlah responden sebanyak $43,5 \%$ sedangkan $21,7 \%$ mendampingi anak belajar dalam waktu 2 jam. Hal ini tentu tidak sesuai apabila kita kaitkan pada masa belajar anak seacra daring semasa pandemi covid 19, anak anak diberikan jadwal belajar sesuai dengan waktu yang ditetapkan sekolah yaitu hampir 6 jam bahkan hingga 8 jam per hari.

Peran serta orangtua pada warga Pamulang Lestari Residence juga masih rendah hanya $34,8 \%$ yang aktif sebagai komite sekolah, sisanya sebanyak $65,2 \%$ tidak ikut terlibat dalam komite, padahal komite sekolah merupakan bentuk peran serta orangtua dalam menjalin hubungan yang baik dengan pihak sekolah. Hal ini tentu perlu dijadikan masukan dan saran untuk perbaikan ke depannya.

Pendidikan dapat sukses dengan bantuan berbagai pihak yang mendukungnya yaitu

\section{Peran Serta Orang Tua}

Terdapat tiga model partisipasi orang tua, yaitu: (1) Protective atau separate responsibities bahwa keluarga dan sekolah memiliki tanggung jawab anak yang saling terpisah dengan menanggani tujuan, target dan kegiatan masing masing, (2) Model school to home transmision atau sequentia bahwa keberhasilan anak didukung oleh nilai nilai yang berasal dari keluarga dan sekolah, (3) Model curriculum Enrichment bahwa interaksi antara personel sekolah dan keluarga dapat mendukung kurikulum sekolah dan tujuan pendidikan, (4) model partneship yang menekankan koordinasi dan kerjasama antara keluarga dan sekolah untuk mengembangkan komunikasi dengan metode sharing atau berbagi pengalaman diantara semua warga sekolah, warga dan masyarakat.

Orang tua dapat berpartisipasi dalam menyediakan dana, prasarana dan sarana sekolah sebagai upaya realisasi program-program sekolah yang telah disusun bersama, serta membina anakanak terutama dalam pendidikan moral agar anak tercegah dari sifat dan perilaku yang kurang baik karena pengaruh lingkungan.

Penjalinan hubungan sekolah dengan orang tua peserta didik dapat dilakukan melalui komite sekolah, pertemuan yang direncanakan atau saat penerimaan raport, sumber informasi sekolah dan sumber belajar bagi anak, serta secara bersama-sama memecahkan masalah.

Adanya Komite Sekolah bertujuan sebagai penghubung masyarakat dengan pemerintah (mediator), pemberi pertimbangan (advisory agency), pendukung kegiatan layanan sekolah (supporting agency), dan pengontrol layanan pendidikan (controlling agency.

Peran Serta Tokoh Masyarakat dan Tokoh Agama 


\section{JURNAL ABDIMAS

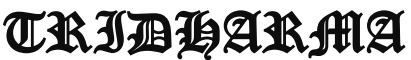

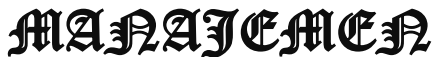

P-ISSN 2615-6849, E-ISSN 2622-3686

Jurnal ABDIMASVol.1,No.3,September 2020,Hal(121-128)

@Prodi Manajemen Fakultas Ekonomi Universitas Pamulang

Email: abdimasjurnal.unpam@ gmail.com Telp: (021) 741-2566
Program kerja sekolah perlu didiskusikan dengan tokoh masyarakat dan agama agar berorientasi pada peningkatan mutu, bukan untuk kepentingan birokrasi.

\section{Peran Serta Dunia Usaha dan} Industri

Peran serta dunia usaha dan industri dapat diwujudkan dalam bentuk partisipasi penggalangan dana, pengadaan fasilitas sarana dan prasarana sekolah, penciptaan relasi eksternal yang dapat memberikan akses yang lebih luas dalam membangun hubungan sekolah dengan masyarakat, serta membantu pengembangan SDM pendidikan, khususnya yang berkaitan dengan teknik-teknik pengembangan mutu.

\section{Peran Serta Kelembagaan Sosial Budaya}

Terdapat jenis-jenis instansiinstansi atau kelompok-kelompok kelembagaan sosial budaya antara lain: paguyuban orang tua siswa, lembaga adat dan tokoh adat, lembaga keagamaan, PKK, kelompok bisnis, kelompok seni, organisasi profesi, gerakan nasional orangtua asuh (GNOTA), puskesmas. Mereka dapat berperan serta dalam menuangkan tenaga, pikiran, keahlian, dana dan lain sebagainya

\section{KESIMPULAN DAN SARAN \\ Kesimpulan}

Kesimpulan kegiatan PKM ini, agar dapat melahirkan sumber daya manusia Indonesia yang dilahirkan melalui proses pendidikan nasional sesuai dengan Undang-undang nomor 20 tahun 2003 ada 9 (sembilan) karakter/ciri syaitu: (1) beriman dan bertakwa kepada Tuhan yang Masa Esa, (2) berakhlak mulia, (3) sehat, (4) berilmu, (5) cakap, (6) kreatif, (7) mandiri, (8) menjadi warga Negara yang demokratis, dan (9) bertanggung jawab.

Peran serta masyarakat terdiri atas elemen tokoh masyarakat, tokoh agama, dunia usaha dan dunia industri, lembaga sosial budaya.

\section{Saran}

Peran serta orang tua dan masyarakat harus terus ditinkatkan terutama dalam pembentukan perilaku atau akhlak yang mulia. Bantuan lainnya juga dapat berupa pengembangan budaya sadar risiko akan bahaya dampak narkoba dan kejahatan seksual dengan membuat kelompok kelompok diskusi terutaama anak yang mulai remaja di lingkungan sekitar

\section{References}

Aressa, v., Nirwana, H., \& Bentri, A. (2016). Komunikasi Interpersonal Anak dan Orangtua ditinjau dari jenis kelamin, Tingkat pendidikan Orangtua dan Daerah tempat Tinggal Serta Implikasinya pada Bimbingan dan Konseling. Jurnal Kounselor Universitas Negeri Padang, 139-150.

BPS. (2019). Potret pendidikan Indonesia ; Statistik pendidikan. Jakarta: Badan Pusat Statistik.

Megawanti, P. (2012). Meretas permaslaahan Pendidikan di Indonesia. Jurnal Formatif Volume 2(3) Program Studi matematika fakultas teknik Universitas Indraprasta PGRI, 2276-234.

Notoatmodjo, S. (2008). Kesehatan dan pembangunan Sumber Daya Manusia . KESMAS, Jurnal 


\section{JURNAL ABDIMAS

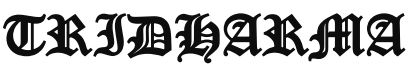

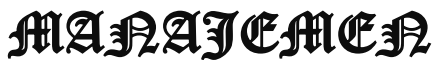

P-ISSN 2615-6849, E-ISSN 2622-3686

Jurnal ABDIMASVol.1,No.3,September 2020,Hal(121-128)

@Prodi Manajemen Fakultas Ekonomi Universitas Pamulang

Email: abdimasjurnal.unpam@gmail.com Telp: (021) 741-2566
Kesehatan Masyarakat

Nasional VOl 2 (5) Universitas

Indonesia , 195-199.

Pasaribu, V. L. D., Susanti, F., \& Hartuti, E. T. K. (2019). Memotivasi Siswa dan Siswi SMK Letris Indonesia di Dalam Menentukan Pilihan Untuk Melanjutkan Pendidikan Atau Bekerja Setelah Lulus Sekolah. Jurnal Pengabdian Dharma Laksana, 1(2), 161-172.

Pasaribu, V. L. D., Agrasadya, A., Shabrina, N., \& Krisnaldy, K. (2020). MENJADI ENTERPRENEUR MUDA YANG MEMILIKI JIWA LEADERSHIP UNTUK MENGHADAPI MASA DEPAN. $A b d i$ Laksana, 1(1).

Pasaribu, V. L. D., Elburdah, R. P., Sudarso, E., \& Fauziah, G. (2020). PENGGUNAAN MANAJEMEN WAKTU TERHADAP PENINGKATAN PRESTASI BELAJAR DI SMP ARAISIYAH. Jurnal ABDIMAS Tri Dharma Manajemen, 1(1).

Pasaribu, V. L. D., Sulaiman, S., Sutiman, S., Thaharudin, T., \& Purnomo, B. Y. (2020). PENGENALAN LETAK POSYANDU TERDEKAT DIKELURAHAN PISANGAN DENGAN MANAJEMEN PEMASARAN REVOLUSI 4.0 UNTUK MENINGKATKAN PENGETAHUAN MASYARAKAT LETAK DAN FUNGSI POSYANDU TERDEKAT PADA KELURAHAN PISANGAN. DEDIKASI PKM, 1(1), 105-110.

Pasaribu, V. L. D., Oktrima, B., Prabowo, B., Arianto, N., \& Haryoko, U. B. (2020). PROGAM PENDAMPINGAN DAN PENYELENGGARAAN

PENDIDIKAN ANAK PADA USIA DINI TERHADAP PRESTASI BELAJAR DILINGKUNGAN RT 020 RW 009. KEL GIRI PENI. KEC WATES. YOGYAKARTA. JURNAL LOKABMAS KREATIF, 1(1), 71-75

Siswanto , H. (2014). Permasalahan pendidikan Dasar dan pendidikan Anak usia Dini. Jurnal CENDEKIA Universitas Islam Blitas Vol 8(2), 137-150.
Sudarsana, I. (2016). Peningkatan Mutu Pendidikan Luar Sekolah dalam Upaya pembangunan Sumber Daya Manusia. Jurnal Penjaminan Mutu vol 1(1) fakultas Gharma Acarya IHDN, 1-14.

Supardi. (2012). Arah pendidikan di Indonesia Dalam Tataran Kebijakan dan Implementasi. Jurnal Formatif Universitas Indraprasta PGRI (UNINDRA), 111-121.

UU. (2003). Undang Undang Nomor 20 Tahun 2003 tentang Sistem Pendidikan Nasional.
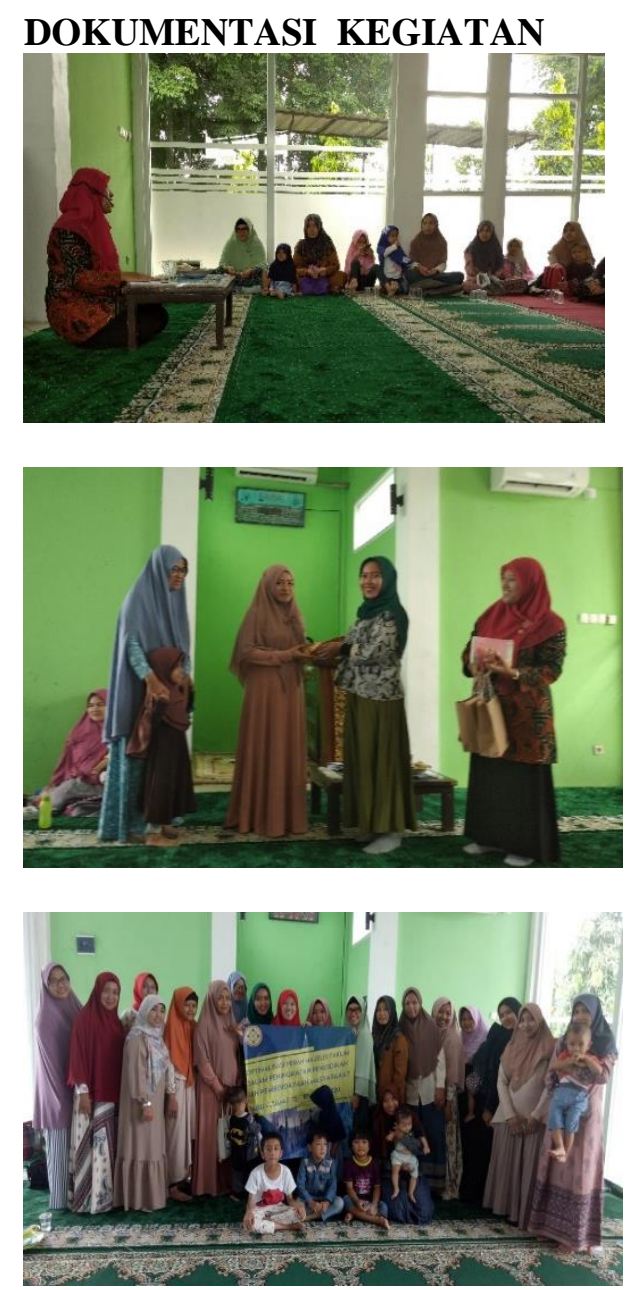